\title{
Medical leadership development during the COVID-19 pandemic
}

\author{
Jan C Frich () , ${ }^{1}$ Clara Bratholm, ${ }^{2}$ Håvard Ravnestad, ${ }^{3}$ Morten L Friberg, ${ }^{4}$ \\ Christer Mjåset, ${ }^{5}$ Oddvar M Kaarbøe ${ }^{1}$
}

${ }^{1}$ Department of Health

Management and Health Economics, University of Oslo,

Oslo, Norway

${ }^{2}$ Division of Paediatrics and

Adolescent Medicine, Oslo

University Hospital, Oslo,

Norway

${ }^{3}$ Department of Cardiology,

Oslo University Hospital, Oslo,

Norway

${ }^{4}$ Department of Internal

Medicine, Vestre Viken Hospital

Trust, Drammen, Norway

${ }^{5}$ The Health Platform,

Trondheim, Norway

\section{Correspondence to}

Professor Jan C Frich,

Department of Health

Management and Health

Economics, University of Oslo,

Oslo, Norway;

jan.frich@medisin.uio.no

Received 24 January 2021

Accepted 27 February 2022
Check for updates

(C) Author(s) (or their employer(s)) 2022. No commercial re-use. See rights and permissions. Published by BMJ.

To cite: Frich JC, Bratholm C, Ravnestad $\mathrm{H}$, et al. BMJ Leader Published Online First: [please include Day Month Year]. doi:10.1136/ leader-2021-000452

\section{ABSTRACT \\ Background A leadership development programme} (The Health Leadership School) was launched in 2018 for junior doctors and medical students in Norway.

Objective To study participants' experiences and self-assessed learning outcomes, and if there were any differences in outcome among participants who met face-to-face versus and those who had to complete half of the programme in a virtual classroom due to the COVID-19 pandemic.

Methods Participants who completed The Health Leadership School in 2018-2020 were invited to respond to a web-based questionnaire.

Results A total of 33 (83\%) out of 40 participants responded. The majority of respondents (97\%) somewhat agreed or strongly agreed that they had gained knowledge and skills they did not learn in medical school. Respondents reported a high learning outcome for most competency domains, and there was no difference in outcome when comparing scores of those who met face-to-face versus and those who had to complete half of the programme in a virtual classroom. Among participants who participated in virtual classroom sessions due to the COVID-19 pandemic, the majority agreed that the programme could be run as a combination of face-to-face and virtual sessions.

Conclusion This brief report suggests that leadership development programmes for junior doctors and medical students can be run in-part using virtual classroom sessions, but that face-to-face sessions are important to foster relational and teamwork skills.

\section{BACKGROUND}

Medical leadership is essential for optimising health system performance. ${ }^{1-3}$ Leadership development programmes can help doctors to build leadership competencies and may also have positive organisational effects, ${ }^{3-6}$ but there is a lack of research on participants' experiences with face-to-face versus virtual classroom learning.

A leadership development programme (The Health Leadership School) was launched in 2018 for young doctors and medical students in Norway. This 1 year postgraduate part-time programme, meriting 15 points in the European Credit Transfer System (ECTS), was developed by junior doctors in the Norwegian Medical Association and University of Oslo. The programme is organised as monthly full-day sessions consisting of lectures, seminars, group work and discussions, with the aim of developing participants' leadership capacity (table 1).

In the first class (2018-2019) there were seven full-day face-to-face sessions. As a consequence of the COVID-19 pandemic, the second class (2019-2020) had to complete the last three full-day sessions in a virtual classroom, using Microsoft Teams.

In this brief report, we study participants' experiences and self-assessed learning outcomes, and if there were any differences in outcome among participants who met face-to-face versus and those who had to complete half of the programme in a virtual classroom due to the COVID-19 pandemic.

\section{MATERIAL AND METHODS}

Among 40 participants (16 participants in the first class and 24 participants in the second class) who completed the programme, there were 27 junior doctors working in hospitals, 4 doctors specialising in general practice, 1 doctor specialising in public health and 8 medical students.

We developed a questionnaire with 15 questions to assess participants' learning outcomes (table 2). For the second class, we added two questions about views on face-to-face versus virtual classroom sessions. We used a 5 -valued Likert scale: 1 (strongly disagree), 2 (somewhat disagree), 3 (neither agree nor disagree), 4 (somewhat agree) and 5 (strongly agree). Participants were allowed to enter free-text comments. We used an online tool (Nettskjema) at University of Oslo to send invitations and to collect responses. Participants were invited to respond anonymously after completion of the programme.

We used SPSS V.27 to analyse the data, calculating mean and SD for responses to each item. The distribution of responses was not normally distributed, and we used Mann-Whitney U-test to compare scores from the two classes. Results with a $\mathrm{p}$ value $<0.05$ were classified as statistically significant. Free-text comments were organised in three thematic categories: comments about the programme, self-assessed learning outcomes and online versus face-to-face teaching.

\section{RESULTS}

A total of 33 (83\%) out of 40 participants responded to the invitation and completed the questionnaire. There were no statistical significant differences when comparing scores for each item in the two classes, and we therefore analysed the results for the group as a whole (table 2).

\section{Self-assessed learning outcomes}

Most respondents (97\%) somewhat agreed or strongly agreed that the programme had given them knowledge and skills beyond what medical school had offered. One participant wrote: 


\begin{tabular}{ll}
\hline Table 1 Description of the programme format and content \\
\hline Format & Content \\
\hline $\begin{array}{l}\text { Lectures, seminars, group work/exercises } \\
\text { and discussion }\end{array}$ & $\begin{array}{l}\text { Introduction to leadership/journey } \\
\text { into leadership. } \\
\end{array}$ \\
& Principles of health economics and \\
& health system financing. \\
& Legal aspects of healthcare. \\
& Teamwork. \\
& Quality improvement. \\
& Service delivery innovation. \\
& Health systems and system level \\
& challenges globally. \\
& The follow a leader exercise: \\
& interview and shadow a leader for \\
& 1 day (submission of a report). \\
& A leadership challenge (submission \\
& of a reflective essay). \\
\hline Individual assignments &
\end{tabular}

It is much clearer for me now what (leadership) involves, and I am very inspired to embark on this kind of work.

The scores were high for learning outcome for most competency domains (table 2).

Areas with lowest score were skills in analysing organisations, discussing and analysing opportunities for service delivery innovation in healthcare, working efficiently as a leader and member of groups and teams and using various strategies to exert influence. All respondents either somewhat agreed or strongly agreed that the 'shadow a leader' exercise gave them insights about the leadership role in practice.

Table 2 Participants' ( $\mathrm{n=33}$ ) self-assessed learning outcomes, on a 5-valued Likert scale from 1 (strongly disagree) to 5 (strongly agree)

\begin{tabular}{|c|c|}
\hline & Mean (SD) \\
\hline \multicolumn{2}{|l|}{ The Health Leadership School has given me... } \\
\hline \multicolumn{2}{|l|}{ Knowledge: The Health Leadership School has given me... } \\
\hline 1. knowledge and skills I did not learn in medical school & $4.8(0.4)$ \\
\hline 2. knowledge of theories and concepts about leadership & $4.8(0.4)$ \\
\hline $\begin{array}{l}\text { 3. knowledge of what influences co-workers' motivation and } \\
\text { engagement }\end{array}$ & $4.6(0.6)$ \\
\hline $\begin{array}{l}\text { 4. knowledge of factors that influence communication and effective } \\
\text { teamwork }\end{array}$ & $4.4(0.6)$ \\
\hline 5. knowledge of quality improvement and service delivery innovation & $4.6(0.6)$ \\
\hline \multicolumn{2}{|l|}{ Skills: The Health Leadership School has given me... } \\
\hline 6. skills in analysing organisations & $4.2(0.6)$ \\
\hline 7. skills in analysing and reflecting on leadership challenges & $4.7(0.5)$ \\
\hline $\begin{array}{l}\text { 8. skills in exploring and analysing dilemmas and conflicts associated } \\
\text { with leadership }\end{array}$ & $4.5(0.6)$ \\
\hline $\begin{array}{l}\text { 9. skills in discussing and analysing opportunities for service delivery } \\
\text { innovation in healthcare }\end{array}$ & $4.3(0.7)$ \\
\hline $\begin{array}{l}\text { 10. skills in working efficiently as a leader and member of groups and } \\
\text { teams }\end{array}$ & $4.2(0.7)$ \\
\hline 11. skills in using various strategies to exert influence & $4.2(0.6)$ \\
\hline \multicolumn{2}{|l|}{ General competencies: The Health Leadership School has... } \\
\hline $\begin{array}{l}\text { 12. made me more reflective on opportunities and limitations related } \\
\text { to exercising leadership in healthcare }\end{array}$ & $4.8(0.5)$ \\
\hline $\begin{array}{l}\text { 13. made me able to reflective concerning bringing about change and } \\
\text { innovation }\end{array}$ & $4.6(0.6)$ \\
\hline $\begin{array}{l}\text { 14. made med more reflective on my own potential for and possibility } \\
\text { to develop myself as a leader }\end{array}$ & $4.6(0.5)$ \\
\hline $\begin{array}{l}\text { 15. given me insights about being a leader through the 'follow a } \\
\text { leader' exercise }\end{array}$ & $4.8(0.4)$ \\
\hline
\end{tabular}

\section{Online education}

We added an additional item in the questionnaire for the second class: 'The Health Leadership School can be undertaken as an online programme'. The 19 participants who responded had diverging views, of which 2 strongly disagreed, 2 somewhat disagreed, 3 neither agreed nor disagreed, 4 somewhat agreed and 5 strongly agreed. Nevertheless, 18 out of 19 somewhat agreed or strongly agreed that the programme could be undertaken as a combination of face-to-face and virtual classroom sessions. One participant wrote: 'I believe it could have been run as an onlineonly programme. However, I did appreciate the physical meetings and the opportunity to practice teamwork'.

\section{DISCUSSION}

Junior doctors and medical students in this leadership development programme reported gaining knowledge and skills they did not learn in medical school. We found no difference in outcome when comparing scores of those who met face-to-face versus and those who had to complete half of the programme in a virtual classroom. All participants interviewed and shadowed a healthcare leader for 1 day, and subsequently wrote a report about the leadership practices and behaviours they have observed and this assignment. This 'follow a leader' assignment received a high score. Participants' feedback suggests that a leadership development programme for junior doctors and medical students can be run in-part using virtual classroom sessions, but that faceto-face sessions are important to foster relational and teamwork skills.

While these findings aligns with previous research, ${ }^{4-6}$ we think the programme in general may benefit from focusing more on relational competencies, team leadership and conflict resolution. ${ }^{5} 7$ Project work in leadership development programmes is associated with positive effects for participants and organisations, ${ }^{6}$ and incorporating team tasks, projects or exercises in the programme may facilitate future participants' competencies in teamwork.

We report self-assessed learning outcomes with a risk of bias towards high scores. ${ }^{8}$ The study's sample size is low. With these methodological shortcomings in mind, we should be careful about drawing conclusions about learning outcomes. Still, in this brief report, we were able to explore if there were any differences in outcome among participants who met face-to-face versus and those who had to complete half of the programme in a virtual classroom due to the COVID-19 pandemic. A study design with objective measures of higherlevel learning outcomes and longitudinal data would be a more suitable to study participants' learning outcomes.

\section{Twitter Jan C Frich @DrFrich}

Contributors JF designed the study, analysed and interpreted the data and drafted the manuscript. $C B, H R, M L F, C M$ and OMK contributed to the design of the study, interpreted the data and revised the manuscript critically for important intellectual content. All authors approved the final version to be published.

Funding The Health Leadership School is funded by Norwegian Medical Association.

Competing interests None declared.

Patient consent for publication Not applicable.

Provenance and peer review Not commissioned; externally peer reviewed.

ORCID iD

Jan C Frich http://orcid.org/0000-0001-9079-7508 


\section{REFERENCES}

1 Mjåset C, Lawerence K, Lee T. Hybrid physicians create 'social capital' for health care. NEJM Catalyst 2020.

2 Goodall A, Stoller JK. The future of clinical leadership: evidence for physician leadership and the educational pathway for new leaders. BMJ Leader 2017;1:8-11.

3 Savage M, Savage C, Brommels M, et al. Medical leadership: boon or barrier to organisational performance? A thematic synthesis of the literature. BMJ Open 2020;10:e035542.
4 Frich JC, Brewster AL, Cherlin EJ, et al. Leadership development programs for physicians: a systematic review. J Gen Intern Med 2015;30:656-74.

5 Mustafa S, Stoller JK, Bierer SB, et al. Effectiveness of a leadership development course for chief residents: a longitudinal evaluation. J Grad Med Educ 2020;12:193-202.

6 Lyons 0, George R, Galante JR, Robynne G G, et al. Evidence-based medical leadership development: a systematic review. BMJ Leader 2021;5:206-13.

7 Stoller JK. Developing physician leaders: does it work? BMJ Leader 2020;4:1-5.

8 Andrade $\mathrm{HL}$. A critical review of research on student self-assessment. Front Educ 2019;4:87. 